\title{
AS MULHERES NO ENSINO SECUNDÁRIO: PERCURSOS DAS PRIMEIRAS PROFESSORAS DO COLÉGIO PEDRO II
}

\author{
WOMEN IN SECONDARY TEACHING: PATHS OF THE FIRST \\ TEACHERS AT COLÉGIO PEDRO II
}

\author{
Paloma Rezende de Oliveira ${ }^{1}$ \\ Nailda Marinho Costa ${ }^{2}$
}

\begin{abstract}
Resumo:
Este texto traz reflexões sobre as professoras pioneiras que atuaram no curso secundário do Colégio Pedro II, na década de 1920, quando, até então, a docência no ensino primário era reservada às mulheres. Foram criadas instituições exclusivas para sua formação, com programas de ensino elaborados por homens, bem como distintos dos programas voltados para as instituições onde o ensino era restrito aos homens, como ocorreu com os cursos secundários, especialmente no século XIX. A integração de mulheres à história do ensino secundário demonstra que estas influenciaram os acontecimentos e tomaram parte na vida pública, à medida que isso lhes foi possível, dentro das condições concretas existentes. Subsidiaram a análise a categoria de gênero vista sob a perspectiva relacional, que busca perceber as relações sociais entre os sujeitos e um modo de dar significado às relações de poder. Fundamenta-se nos pressupostos teóricos de Perrot (2012) e Scott (1990) bem como na noção de intelectuais "mediadores culturais" de Gomes e Hansen (2016).

Palavras-chave: Magistério secundário. Colégio Pedro II. Gênero.
\end{abstract}

\begin{abstract}
:
This text brings reflections on the role of pioneer women teachers in secondary teaching at Colégio Pedro II, in the 1920s, when until then, teaching in primary education was reserved for women. Exclusive institutions were created for their training, with teaching programs designed by men, as well as programs different from the ones aimed at institutions where teaching was restricted to men, as it was the case of secondary education, especially in the 19th century. The integration of women in the history of secondary education shows they influenced events and took part in public life, as far as possible, within the existing concrete conditions. The analysis supported the gender category seen from a relational perspective, which seeks to understand the social relations between the subjects and a way of signifying the power relations. It is based on the theoretical assumptions of Perrot (2012) and Scott (1990) as well as on the notion of intellectuals "cultural mediators" of Gomes and Hansen (2016). Keywords: Secondary teaching. Colégio Pedro II. Gender.
\end{abstract}

As professoras secundárias e seu papel como intelectuais mediadoras culturais

\footnotetext{
1 Professora da Universidade do Estado de Minas Gerais - UEMG - Unidade Carangola. E-mail: paloma.oliveira@uemg.br

${ }_{2}^{2}$ Professora titular da Universidade do Estado do Rio de Janeiro - Unirio. E-mail: nailda.costa@unirio.br
} 


\section{HISTÓRIA}

Dossiê: Ensino de História, História das Mulheres e Desigualdades Sociais no Brasil

Este estudo sobre a atuação das mulheres como professoras no ensino secundário partiu de reflexões sobre as condições e circunstâncias que fizeram com que as mulheres, cujo locus de formação e atuação eram, respectivamente, as Escolas Normais e o ensino primário, passassem a ocupar espaço também no quadro docente dos cursos secundários.

Isso porque os cursos secundários, como por exemplo o Colégio Pedro II (CPII), tiveram ao longo do século XIX, o quadro docente composto unicamente por homens, sendo preciso pensar, então, o que possibilitou essa mudança na composição do magistério secundário, bem como os aspectos do percurso profissional dessas primeiras professoras que viabilizaram seu ingresso na instituição, de modo a percebermos as estratégias identitárias por elas construídas.

Nos primeiros levantamentos realizados no NUDOM - Núcleo de Documentação e Memória do $\mathrm{CPII}^{3}$, foram localizadas quatro professoras que atuaram no externato ${ }^{4}$ como suplentes e no internato como auxiliares. Em 1926, Maria da Glória Ribeiro Moss, foi a primeira mulher a ingressar. Ela atuou nas aulas de Química do externato; em 1927, Maria de Lourdes (Português) e Aimée Ruch (Francês), que lecionaram as línguas modernas; e além destas três, a partir desse mesmo ano, Carmem Portinho, que trabalhou como auxiliar nas turmas de Aritmética, no internato. Outros estudos sobre "a presença feminina" no CPII, contudo, apontaram que a inserção das mulheres na instituição se deu inicialmente no corpo discente

\footnotetext{
3 O NUDOM foi criado pela Portaria $n^{\circ} 1.019$, de 22/08/1995, pelo então diretor do CPII, o professor Wilson Choeri. Localizava-se no prédio da Unidade Escolar Centro, local onde foi instalado o Imperial Colégio de Pedro II, em 1837, antes Seminário de São Joaquim, reformado para pelo arquiteto Grandjean de Montigny para que fosse ocupado pelo renomado Colégio secundário para meninos. $\mathrm{O}$ Núcleo constitui-se como um guardião da memória coletiva, "tanto pelos documentos únicos referentes à história do Colégio, como pelas memórias de seus antigos alunos e professores, registradas em livros, depoimentos escritos e orais e imagens que retratam a marca muito característica de uma formação educacional" (SANTOS, 2013, p.40).

${ }^{4} \mathrm{O}$ art. $1^{\circ}$ do Decreto $\mathrm{n}^{\circ} 2.006$, de 24 de outubro de 1857, que regulamentou os colégios públicos de instrução secundária do Município da Corte, assinado pelo Marques de Olinda - Conselheiro d'Estado, Presidente do Conselho de Ministros, Ministro e Secretario d'Estado dos Negócios do Império, com a anuência do Imperador Pedro II, estipulou que o "Colégio de Pedro II" seria dividido em dois estabelecimentos de instrução secundária, denominados Internato e Externato do "Imperial Colégio de Pedro II" (BRASIL, 1857).
} 


\section{HISTÓRIA}

Dossiê: Ensino de História, História das Mulheres e Desigualdades Sociais no Brasil

(Alves, 2009; Andrade, 2000; Marinho, 2016) ${ }^{5}$. E, com isso, a admissão de professoras se tornou necessária como regentes de turma.

A análise do percurso profissional das primeiras professoras do Colégio Pedro II não se pautou somente no trabalho que desenvolveram na instituição, mas também em elementos que ajudaram a configurar sua formação, bem como suas atuações em outros espaços públicos, tais como: associações, sociedades, instituições escolares, sindicatos, imprensa, etc.

Por isso, buscamos também estabelecer possíveis aproximações entre estas professoras e a acepção de intelectual trazida por Gomes e Hansen (2016), segundo a qual, este é percebido como mediador cultural, diferenciando-se da perspectiva tradicional da história política, que atribui esta categoria às pessoas que cultivam desinteressadamente a universalidade do espírito.

Desse modo, as professoras destacadas neste trabalho são vistas como sujeitos da produção de conhecimentos e da comunicação de ideias, podendo estar direta ou indiretamente vinculadas à intervenção político-social e são também consideradas sujeitos estratégicos nas áreas da cultura e da política, ocupando posição de reconhecimento na vida social. Estas mulheres, são tratadas aqui tendose como base suas práticas como Intelectuais mediadoras uma vez que elaboram, defendem e divulgam suas ideias tal como proposto por Gomes \& Hansen (2016), ao atuaram como escritoras, professoras, autoras, dentre outros, passam a integrar esta categoria, sendo necessário conhecer suas experiências, percursos e estratégias intelectuais (GOMES e HANSEN, 2016).

Por outro lado, a (re)construção de seus percursos ainda se constitui um desafio, no sentido de se estabelecer relações mais significativas entre suas histórias

\footnotetext{
${ }^{5}$ A presença de meninas no corpo discente retroage ao ano de 1883 , no Externato do CPII. Contudo, essa será provisória, permanecendo até 1889 , sendo as meninas transferidas para escolas "adequadas ao seu sexo", como a Escola Normal. Entre as alunas matriculadas estavam as filhas de Candido Barata Ribeiro. Ocupava a Pasta do Império, o senador Pedro Leão Velloso, que autorizou o reitor da instituição a adminitr no externato "alunas do sexo feminino", conforme de 22 de fevereiro de 1883, por não existir disposição legal proibitiva. Em 1926, a menina Yvone Monteiro da Silva será a primeira matriculada para a turma do ano de 1927 (BONATO, 2005, 145; MARINHO, 2016, p.221).
} 


\section{HISTÓRIA}

Dossiê: Ensino de História, História das Mulheres e Desigualdades Sociais no Brasil

individuais e suas histórias coletivas, que não pode se dar dissociada da sociedade onde está inserida (OLIVEIRA; COSTA, 2019)

Desse modo, este artigo se inscreve nos estudos sobre a "História das mulheres", tanto no Brasil quanto na América Latina, os quais admitiram Georges Duby e Michelle Perrot na obra "História das mulheres no Ocidente", de 1991, estiveram ausentes, devido à 'inexistência de estudos', sobre o assunto nessa região. Segundo Costa e Xavier (2019), estudos sobre a história de gênero e das mulheres, evidenciaram que: "Al largo de treinta años, la historia de las mujeres cambió sus objetivos y en sus pontos de vista". As autoras corroboram a afirmação de Michele Perrot de que "(...) se fue ampliando hasta volverse más específicamente una historia del género, que insiste en las relaciones entre los sexos e integra la masculinidade" (PERROT, 2012, apud COSTA; XAVIER, 2019, p.378) ${ }^{6}$.

A concepção de gênero, enquanto "categoria de análise", viabiliza perceber as relações entre os sujeitos e um modo de significar as relações de poder (Scott, 1990). No caso aqui, refere-se também aos professores do sexo masculino que atuavam no CPII, ou seja, implica em pensar as relações estabelecidas entre os pares e também os outros. Em seu sentido mais restrito, refere-se aos estudos que têm a mulher como objeto, em um sentido mais amplo, é entendido como uma construção social, histórica e cultural, elaborada sobre as diferenças sexuais. Portanto, não nos deteremos especificamente a um ou outro sexo, mas sobre as relações que são socialmente construídas entre eles e que estão estreitamente ligadas, por sua vez, às relações de poder, que revelam os conflitos e as contradições que marcam a sociedade em determinada temporalidade ou espaço. Há que se considerar também que o sujeito

\footnotetext{
${ }^{6}$ As discussões, iniciadas no final da década de 1960, nos espaços acadêmicos trabalhavam com o termo "mulher", sendo o debate aprofundado com a crítica a uma ideia de "condição feminina". Depois da década de 1980 a utilização do termo passou a ser substituída, gradativamente, por "gênero". Essa nova perspectiva eliminou o determinismo biológico enraizado na utilização de termos como "sexo" ou "diferença sexual", considerando a construção cultural e social. Com a proposta de gênero, os homens assumiram espaço no campo de estudos, já que este não se pautava no enfoque dos indivíduos femininos, mas sim nas condições sociais e nas relações esta estabelecidas entre eles (ZUCCO, 2020, p.37).
} 


\section{HISTÓRIA}

Dossiê: Ensino de História, História das Mulheres e Desigualdades Sociais no Brasil

histórico não é universal ou assexuado, nem há categorias de análise que deem conta da complexidade da vida como um todo. A abordagem de gênero serve para evidenciar que tanto os homens quanto as mulheres só podem ser analisados, identificados ou diferenciados entre si, nas relações que estabelecem e se ultrapassarmos as diferenciações puramente naturais entre os sexos (ALMEIDA, 1998).

De acordo ainda com o autor, o pressuposto da inferioridade biológica e intelectual feminina, presente no século XIX, considerou natural alicerçar os homens no poder. Com base nesta diferença, justificava-se a subordinação feminina e seu alijamento da esfera pública. A participação política das mulheres, bem como na educação secundária e superior, continuou restrita a um pequeno grupo, que pertencia a uma classe social mais abastada. E, apesar de se conceder algumas parcelas do saber às mulheres, este não se distribuiu equitativamente, assim como o poder. Isso porque, tanto nas escolas quanto na sociedade, a hegemonia masculina apropriou-se do controle educacional, seja por meio da restrição do acesso seja ditando regras e normatizações da instrução, que limitavam o acesso das mulheres às profissões por eles determinadas, tais como o magistério secundário.

(...). Para viabilizar esse poder na educação escolar, elaboraram leis e decretos, criaram escolas e liceus femininos, compuseram seus programas de ensino, escreveram a maioria dos livros didáticos e manuais escolares, habilitaram-se para a cátedra das disciplinas mais nobres, segregando as professoras a guetos femininos (...) (ALMEIDA, 1998, p.35).

Essa noção de dominação masculina que a princípio designa desigualdade nas relações sociais, obteve uma nova significação através do conceito de gênero, excluindo a ideia de algoz e vítima nas relações entre os sexos. Com isso, o estudo de gênero parte do princípio da própria diferença biológica entre os sexos, mas também das diferenças entre os seres humanos independentes do sexo, ou seja, considera outras características são levantadas como idade, nação, raça, religião, cultura, tudo que é comum à humanidade (COSTA, 2003, p. 190).

Se analisarmos o contexto do CPII, podemos notar através dos estudos sobre a identidade do magistério secundário e sobre a presença de mulheres nesta 


\section{HISTÓRIA}

Dossiê: Ensino de História, História das Mulheres e Desigualdades Sociais no Brasil

instituição, que tal hegemonia masculina se fez presente, sobretudo no século XIX, com sensível mudança na década de 1920, quando Euclides de Medeiros Guimarães Roxo assumiu a gestão do Colégio. Tem-se que levar em consideração também o impacto que a produção intelectual dessas professoras teve para o programa de ensino dos cursos secundários, como também em outros espaços públicos, para além do educacional.

A dificuldade encontrada pelas mulheres de ingressar no ensino superior e de cursar o ensino secundário deve-se, segundo aponta Heleieth Saffiotti (2013, p.208), ao fato de que o Colégio Pedro II no Império era destinado exclusivamente aos meninos e tinha caráter propedêutico. Os exames, inicialmente realizados apenas nesse estabelecimento de ensino constituíam, pois, verdadeiro empecilho aos estudos superiores femininos.

As professoras no corpo docente do CPII: A reforma do ensino secundário na gestão de Euclides Roxo

Em um estudo de Valente (2003), sobre as etapas históricas da Matemática, em que se debate a primeira reforma internacional desta disciplina, foi possível perceber indícios de que a proposta de modernização do ensino secundário, por Euclides Roxo ${ }^{7}$, relaciona-se com o ingresso de mulheres no quadro docente do Colégio Pedro II. Dentre os aspectos levantados que consideramos ter de algum modo contribuído com este ingresso, podemos citar: a expansão das turmas suplementares; o aumento do número de alunos, inclusive gratuitos; a presença feminina no corpo discente; a nomeação de professoras suplementares ${ }^{8}$ pelos professores catedráticos para as cadeiras de línguas e ciências modernas, implementadas pela Reforma

\footnotetext{
${ }^{7}$ Euclides Roxo foi aluno do Internato do CPII, bacharelando-se nesse Colégio em 1909. Em 1916, formou-se Engenheiro Civil na Escola Politécnica (RJ), antes, em 1915, foi aprovado para professor substituto de Matemática do CPII e depois nomeado professor catedrático (DASSIE, 2008; 2011).

8 Segundo Soares $(2014$, p.207), os professores suplementares também eram chamados na documentação de "regentes estranhos", "pessoas estranhas", "elementos estranhos", "professores estranhos", ou seja, não catedráticos, sem vínculo empregatício efetivo. São aqueles professores contratados temporariamente, com o intuito de contornar dificuldades, tais como: a falta de docentes face ao aumento do número de turmas suplementares, que ficavam a cargo do professor catedrático, podendo chegar a até 4 turmas por professor.
} 


\section{HISTÓRIA}

Dossiê: Ensino de História, História das Mulheres e Desigualdades Sociais no Brasil

Francisco Campos, partir do Decreto n 19.890, de 11 de abril de 1931 (BRASIL, 1931); formação acadêmica vinculada à matéria lecionada.

Estas mudanças foram aos poucos sendo implementadas por Euclides Roxo, quando este assumiu a cadeira como professor catedrático, em 1919, em substituição ao professor Eugênio de Barros Raja Gabaglia. Ele se tornou diretor do externato em 1925 e, de 1930 até 1935, do internato. Euclides Roxo, como diretor do CPII, parece ter sido o promotor da admissão das mulheres como parte integrante de um projeto que propunha a modernização do ensino na instituição. Ele foi considerado o protagonista do primeiro movimento modernizador do programa de ensino secundário, ocorrido no Brasil, ao tentar implementar a reforma no ensino de matemática ocorrido na Alemanha, e liderada por Felix Klein (1849-1925) ${ }^{9}$, que se orientava por realizar o ensino da Aritmética, Álgebra e Geometria em uma única disciplina, a Matemática, como explica Valente (2003).

Conforme esse autor, a reforma se orientava por realizar o ensino da Aritmética, Álgebra e Geometria em uma única disciplina, a Matemática, e havia encontrado resistência do professor Raja Gabaglia e do professor Almeida Lisboa, que adotavam os livros didáticos da coleção FIC, desde 1895. Estes livros foram substituídos, em 1922, pelos de autoria de Euclides Roxo, o que somente foi possível devido a uma viagem daquele último para o exterior, e devido ao apoio dos professores Arthur Thiré e Henrique Costa. O livro passou a ser adotado em 1923, permanecendo até 1929.

Afirma Zuin (2016), que a reforma proposta por Roxo pautada no ensino intuitivo foi implementada no CPII, pelo Decreto $\mathrm{n}^{\circ}$ 18564, de 15 de janeiro de 1929, demonstrando estar acompanhando o movimento renovador. Schelbauer (2006) explica que o ensino intuitivo parte da premissa de que a educação deve começar pela educação dos sentidos, estabelecendo uma nova relação entre as ciências naturais e a educação. A intuição sensível, a primeira etapa do método, é conhecida também sob a denominação de lições de coisas. Esse saber difundido no final do século XIX, no Brasil, trouxe elementos de renovação pedagógica, em relação ao ensino livresco, se fazendo presente nas primeiras décadas do século seguinte.

\footnotetext{
${ }^{9}$ Felix Klein (1849 - 1925), nascido em 25 de abril na cidade Düsseldorf, Alemanha, no início do século XX, ocupou um lugar de grande visibilidade nos debates da comunidade matemática. Para saber mais ver Souza (2010).
} 


\section{HISTÓRIA}

\section{Dossiê: Ensino de História, História das Mulheres e Desigualdades Sociais no Brasil}

Naquele mesmo ano em que a reforma foi implementada, Euclides Roxo também passou a integrar o conselho diretor da Associação Brasileira de Educação (ABE), entidade fundada em 1924 e, posteriormente, foi convidado por Francisco Campos, então Ministro da Educação e Saúde Pública, durante o governo de Getúlio $\operatorname{Vargas}^{10}$, para participar da reformulação do ensino nos moldes que já havia sido implantado no CPII, sendo responsável pelos programas de Matemática da Reforma Francisco Campos de 1931, e pela implementação das turmas suplementares de línguas modernas nos cursos secundários. Roxo atuou também na Reforma Gustavo Capanema $^{11}$, de 1942 (ZUIN, 2016).

A introdução do ensino das línguas modernas no programa de ensino do CPII, com a Reforma de 1932, também foi um dos aspectos que possibilitou que as mulheres entrassem no ensino secundário como docentes. O número de professoras auxiliares de Português, Francês e Inglês ampliou, após a introdução do método direto no ensino de línguas vivas, nas duas primeiras séries do curso secundário. Desse modo, as mulheres puderam ingressar no corpo docente, contudo, apesar de algumas delas apresentarem formação superior, a não admissão como professoras catedráticas, via concurso, leva-nos a pensar sobre a tentativa de garantir a permanência da hegemonia e a manutenção do prestígio atribuído ao cargo restrito aos homens, visto que somente os catedráticos podiam integrar a Congregação de professores e as comissões de ensino, responsáveis por implementar e estruturar os programas de ensino.

O mesmo pode-se perceber sobre a ocupação dos cargos administrativos que, por sua vez, somente foram ocupados por mulheres em 1979, sendo a professora

\footnotetext{
${ }^{10} E m$ 1930, Francisco Campos assume o recém-criado Ministério da Educação e Saúde. Em 1931, é reformulado o ensino secundário. O Decreto $n^{\circ} 21241$, de 1932, consolida as disposições sobre a estruturação dos cursos secundários. Quanto ao ensino de Matemática, são acatadas as ideias renovadoras de Euclides Roxo, já adotadas no CPII (BRASIL, 1932).

${ }^{11}$ Em 1934, Gustavo Capanema assume o Ministério da Educação e Saúde. Para debater o ensino secundário, a ABE promoveu uma série de conferências, entre os conferencistas estava Euclides Roxo. É somente em 4 de abril de 1942 que será promulgada a Lei Orgânica do Ensino Secundário. Euclides Roxo fez parte da comissão responsável pela elaboração dos programas de Matemática. Para Clarice Nunes (2001, p.104), "A implantação do Estado Novo encerra o movimento das reformas de ensino em vários estados brasileiros e no Distrito Federal, conhecido como Movimento da Escola Nova". Como afirma a autora, Francisco Campos e Gustavo Capanema propunham uma escola secundária para formar a elite intelectual em contraponto a um grupo da ABE, entre eles, Anísio Teixeira, que na reforma de instrução pública do Rio de Janeiro introduziu no nível secundário, o ensino profissional técnico, valorizando o diploma dessa escola como equivalente aos cursos secundários acadêmicos, dessa forma, ampliando o número de alunos nas escolas técnicas secundárias.
} 


\section{HISTÓRIA}

Dossiê: Ensino de História, História das Mulheres e Desigualdades Sociais no Brasil

Maria Leda de Moraes Chini, a primeira e única mulher que assumiu a direção do Externato Bernardo de Vasconcelos ${ }^{12}$, hoje extinto (ALVES, 2009).

As condições de trabalho das professoras do Colégio Pedro II

A partir dos dados levantados nos relatórios dos diretores Euclides Roxo (1928) e Pedro Coutto (1932), presentes no Arquivo do NUDOM/CPII, e na documentação apresentada na tese de Soares (2014), foi possível constatar um aumento significativo do número de professoras entre os anos de 1930 e 1940, em relação aos primeiros anos de sua atuação.

Em 1926, ingressou a primeira professora, Maria da Glória Ribeiro Moss; e, em 1927, mais três professoras: Aimée Ruch, que lecionava aulas de Francês; Carmem Portinho, Aritmética; e Maria de Lourdes Nogueira, Português. Já em 1940, foram localizadas 39 professoras, de um total de 219 professores, as quais atuavam como suplementares no CPII, em especial nas línguas modernas, sendo 5 professoras de Português, 19 de Francês e 9 de Inglês. Além destas, havia ainda duas professoras que lecionavam Geografia; uma, Química; uma, Ciências Físicas e Naturais, e duas, História da Civilização. Também foi possível localizar os nomes destas professoras que atuaram em 1940 nas turmas suplementares, e alguns dos registros no Departamento Nacional de Ensino - DNE - em que constavam, além do número de inscrição, as considerações sobre aspectos morais das professoras.

QUADRO 1: Professoras suplementares do Colégio Pedro II - 1940

\begin{tabular}{|l|l|l|l|}
\hline Português & Francês & Inglês & Outras matérias \\
\hline$\underline{\text { Maria de }}$ & $\begin{array}{l}\text { Maria Las Casas A. Souza } \\
\text { Lourdes }\end{array}$ & $\begin{array}{l}\text { Alda Drumond (n. } \\
\text { (n. 1491) }\end{array}$ & $\begin{array}{l}\text { Anna O. Porto Carrero } \\
\text { (Geografia) }\end{array}$ \\
\hline
\end{tabular}

\footnotetext{
12 Bernardo Pereira de Vasconcelos foi ministro do Império. Fundador e idealizador do Colégio Pedro II. Nos primeiros anos do Colégio, foi responsável pela indicação dos primeiros docentes e pela escolha do material didático adotado. Com a República, a instituição teve o nome alterado para Instituto de Instrução Secundária (1889), Externato Nacional Pedro II e Internato Nacional Bernardo Pereira de Vasconcelos (1909). Em 1911, retomaria sua primitiva designação, Externato Bernardo de Vasconcelos. Fonte: Colégio Pedro II. Disponível em: $<$ http://cp2.g12.br/118progesp/index.php?option=com content\&view=article\&id=1865> $<$ http://cp2centro.net/?p=4765 >. Acesso em 15 mai. 2020.
} 


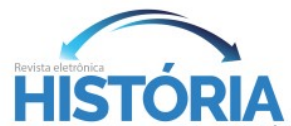

Dossiê: Ensino de História, História das Mulheres e Desigualdades Sociais no Brasil

\begin{tabular}{|c|c|c|c|}
\hline$\frac{\text { Nogueira }}{(\mathrm{n} .199)}$ & & & \\
\hline $\begin{array}{l}\text { Aurea de Salles } \\
\text { Pereira Leite }\end{array}$ & Nair Quintella (n.7017) & $\begin{array}{l}\text { Candelária Lima } \\
\text { Mendes }\end{array}$ & $\begin{array}{l}\text { Nadir Raja Gabaglia } \\
\text { (Geografia) }\end{array}$ \\
\hline Clara Oiticica & Aimée Ruch (n.1179) & $\begin{array}{l}\text { Diva Alves Pinto } \\
(\mathrm{n} .1332)^{*}\end{array}$ & $\begin{array}{l}\text { Maria da Glória Moss } \\
\text { (Química) }\end{array}$ \\
\hline $\begin{array}{l}\text { Anna da } \text { Glória } \\
\text { Santos de } \\
\text { Araújo }\end{array}$ & Alice Santour & $\begin{array}{l}\text { Maria Pinheiro } \\
\text { Guimarães }\end{array}$ & $\begin{array}{l}\text { Nilda Bethlen (Ciências } \\
\text { Físicas e Naturais) }\end{array}$ \\
\hline \multirow[t]{16}{*}{ Otília Reis } & Amalia Honold & Melissa Hull* & $\begin{array}{ll}\text { Wanda de Mattos } \\
\text { Cardoso (História da } \\
\text { Civilização) n.4673 }\end{array}$ \\
\hline & $\begin{array}{l}\text { Amalia Caminha Machado } \\
\text { (n.2375) }\end{array}$ & Mary Mandin & $\begin{array}{l}\text { Zuleide Cesar } \\
\text { Burlamaqui (História } \\
\text { da Civilização) }\end{array}$ \\
\hline & Eva Manuel & $\begin{array}{l}\text { Maria dos Reis } \\
\text { Campos (n.1229) }\end{array}$ & \\
\hline & Felicidade Petit Lopes* & $\begin{array}{ll}\text { Sidronia } & \text { C. } \\
\text { Guimarães } & \end{array}$ & \\
\hline & Gilda de Carvalho (n. 1357) & Eridéa de Barros & \\
\hline & $\begin{array}{l}\text { Laura Sampaio Vianna }(\mathrm{n} . \\
5144)\end{array}$ & & \\
\hline & $\begin{array}{l}\text { Maria de Lourdes Sá } \\
\text { Pereira* }^{*}\end{array}$ & & \\
\hline & $\begin{array}{l}\text { Madaleine Manuel } \\
\text { (n. 4674)* }\end{array}$ & & \\
\hline & Mary Lucy Torres Martins & & \\
\hline & Maria Velloso* & & \\
\hline & Nadir Raja Gabaglia & & \\
\hline & Silvia Falleti ${ }^{\star}$ & & \\
\hline & $\begin{array}{l}\text { Clara de Paiva Galvão (n. } \\
547 \text { ) }\end{array}$ & & \\
\hline & $\begin{array}{l}\text { Francisca de Almeida } \\
\text { Aguiar (n. 1868) }\end{array}$ & & \\
\hline & Lucia Uchôa Cavalcanti & & \\
\hline & Maria Chermont Costa & & \\
\hline TOTAL: 5 & 19 & 9 & 6 \\
\hline
\end{tabular}




\section{HISTÓRIA}

Dossiê: Ensino de História, História das Mulheres e Desigualdades Sociais no Brasil

Quadro elaborado pelas autoras com base na tese de Soares (2014, p.134-137) e nos relatórios dos diretores: Euclides Roxo (1928) e Pedro Coutto (1932), localizados no acervo do NUDOM/CPII.

No quadro, as professoras suplementares de línguas modernas foram sinalizadas por um asterisco, são elas: Felicidade Petit Lopes, Maria de Lourdes Sá Pereira, Madaleine Manuel (n. 4674), Maria Velloso, Silvia Falleti (Francês); Diva Alves Pinto (n. 1332) e Melissa Hull (Inglês). O número constante ao lado do nome da professora demarca aquelas que tinham registro no Departamento Nacional de Ensino.

Embora os dados apresentados façam referência ao ano de 1940, as professoras que atuaram no externato ${ }^{13}$ do CPII, durante 1926 e 1927, estão presentes na lista apresentada, são elas: Maria da Glória Ribeiro Moss, Maria de Lourdes Nogueira e Aimée Ruch, o que confirmou que foram "esquecidas" ou mesmo desconsideradas pelo professor Escragnolle Doria, ${ }^{14}$ em sua obra sobre o centenário do Colégio de Pedro Segundo, intitulada Memória histórica do Colégio de Pedro Segundo - 1837-1937, publicada em 1939. A obra também não menciona o fato de que, em 1932, o número de professoras auxiliares de Francês e Inglês ampliou, com a introdução do método direto para o ensino de línguas vivas nas duas primeiras séries do curso secundário. Com isso, as mulheres puderam ingressar no quadro docente, conforme representado no quadro.

De um total de 19 professoras suplementares de Francês, apenas 9 apresentavam o registro, sendo a maioria classificada como bom elemento. E em relação às nove professoras suplementares de Inglês, apenas três.

Além das professoras suplementares de línguas modernas, que eram a maioria, havia também professoras suplementares de Geografia, Química, Ciências Físicas e Naturais e de História da Civilização. A avaliação das professoras chamou atenção para as representações construídas sobre seu perfil profissional, a partir do olhar de seus pares, em especial a de Nilda Bethlen, por se distinguir das demais por

\footnotetext{
${ }^{13} \mathrm{O}$ art. $1^{\circ}$ do Decreto $\mathrm{n}^{\circ} 2.006$, de 24 de outubro de 1857 que regulamentou os colégios públicos de instrução secundária do Município da Corte, assinado pelo Marques de Olinda - Conselheiro d'Estado, Presidente do Conselho de Ministros, Ministro e Secretario d'Estado dos Negócios do Império, com a anuência do Imperador Pedro II, estipulou que o "Colégio de Pedro II" seria dividido em dois estabelecimentos de instrução secundaria, denominados Internato e Externato do "Imperial Colégio de Pedro II" (BRASIL, 1857).

${ }^{14}$ Alguns aspectos sobre Luiz Gastão de Escragnolle Dória (1869-1948), como professor do CPII, foram retratados no estudo de Gama e Mello (2017).
} 


\section{HISTÓRIA}

Dossiê: Ensino de História, História das Mulheres e Desigualdades Sociais no Brasil

trazer considerações sobre sua aparência e experiência: é quase uma criança. Substitui a irmã, casada com militar transferido para o Mato Grosso. Inexperiente (SOARES, 2014, p.134-137).

Em 1940, o aumento do número de mulheres se deu também em relação às discentes, o que já vinha ocorrendo desde 1927, bem como o aumento do número de alunos gratuitos ${ }^{15}$ no CPII.

Embora não se possa desconsiderar que esta ampliação veio acompanhada de certa precarização do trabalho, haja visto a maioria das professoras não terem registro na Diretoria Nacional de Ensino, as análises que se baseiam no pressuposto de declínio das instituições, de François Dubet (2002), precisam tomar o cuidado de não acabarem por enfatizar a dicotomia entre homens e mulheres, reforçando a prerrogativa de que os antigos professores passaram a ganhar outros espaços de atuação e formação, deixando as instituições em busca de novas ou melhores condições de trabalho, sendo então os cargos deixados por eles, ocupados pelas mulheres. Tal pressuposto corrobora a tese, segundo a qual os "homens mundo", que segundo Mendonça, Soares e Lopes (2013) e Mendonça (2015) ocuparam as cátedras do CPII, não tinham na docência sua principal profissão, vendo o prestígio da instituição onde atuavam apenas como um trampolim para alcançarem melhores cargos.

Para além desta concepção, apontada por Soares e Silva (2018), pautada na ideia de que a crise institucional do CPII teria se iniciado na década de 1930, com a Reforma Francisco Campos, devido a problemas na infraestrutura, baixos rendimentos dos professores, aumento do número de alunos e de turmas suplementares e que culminou na criação do curso de Filosofia para formação de professores em nível superior no CPII, desponta a perspectiva que considera relevante, para explicar a presença de mulheres na instituição, as reivindicações dos grupos feministas, bastante atuantes no período. Como exemplo, podemos citar a primeira Conferência pelo Progresso Feminino, realizada em $1922^{16}$, onde as

\footnotetext{
15 Os alunos do CPII pagavam anuidade (ANDRADE, 2016). Dessa forma, passaram a conviver com os alunos que não podiam pagar.

${ }^{16}$ As mulheres no corpo discente do Colégio foi ponto de pauta da Comissão de Educação da Primeira Conferência pelo Progresso Feminino, realizada em 1922, pela Federação Brasileira pelo Progresso Feminino, entidade presidida por Bertha Lutz.
} 


\section{HISTÓRIA}

Dossiê: Ensino de História, História das Mulheres e Desigualdades Sociais no Brasil congressistas reivindicavam a entrada de mulheres no Colégio Pedro II, instituição de nível secundário exclusiva para o sexo masculino e passaporte para o ensino superior (BONATO, 2005).

Com base no pressuposto de que as discriminações hierarquizam as categorias de pertencimento também no interior dos estabelecimentos de ensino, este tipo de análise possibilita pensar que as mulheres ingressaram no CPII como estratégia para se distinguirem dos ofícios de imagem social negativa ou com posição subordinada, e que não exigiam qualificação, sem, no entanto, ter como preocupação central os aspectos que as distinguiam das demais mulheres e entre si.

Foi possível também estabelecer relações de parentesco entre os professores do CPII e as primeiras professoras que ingressaram no final da década de 1930, contudo, há indícios ainda mais fortes de que a ocupação destes cargos foi viabilizada por um projeto modernizador do ensino secundário promovido pelo diretor Euclides Roxo, que vinha sendo implementado na instituição.

Logo, o que para alguns representava uma perda de prestígio, para outros indicava não apenas a modernização do ensino, como também a ampliação do acesso gratuito ao ensino secundário, a coeducação e o alcance das reivindicações das pautas feministas.

Uma síntese do percurso profissional das primeiras professoras

Como vimos, em 1926, a primeira professora a ingressar no CPII foi Maria da Glória Ribeiro Moss. E, em 1927, compuseram este quadro Aimée Ruch, Carmem Portinho e Maria de Lourdes Nogueira.

Nesta parte, nos detivemos em sintetizar alguns apontamentos iniciais sobre o percurso destas quatro mulheres, a partir do levantamento das fontes do NUDOM/CPII e da imprensa disponível na Hemeroteca da Biblioteca Nacional.

A imprensa se mostrou uma rica fonte de pesquisa sobre estas professoras, uma vez que muito de sua atuação e participação nos diversos espaços públicos foram nela retratadas, complementando ou permitindo contrapor os dados levantados 


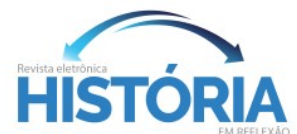

Dossiê: Ensino de História, História das Mulheres e Desigualdades Sociais no Brasil

na documentação do acervo do arquivo do CPII, ou mesmo em pesquisas anteriores sobre a temática.

Na tese da professora Maria da Glória Ribeiro Moss, apresentada durante o concurso em que ela se candidatou à vaga de professor catedrático de Química do CPII, em 1939, consta referência à carta de indicação feita por Euclides Roxo, que, como vimos, além de professor catedrático de matemática, também foi diretor do Externato, quando ela iniciou seus trabalhos no CPII. Quando começou a atuar no CPII, já havia se formado em Farmácia e exercido o magistério na Escola Normal. Posteriormente, formou-se também para exercer a profissão de advogada, o que se deu de forma concomitante à atuação em diferentes escolas secundárias e de ensino profissional no município do Rio de Janeiro, entre os anos de 1931 a 1937 (MOSS, 1933; 1939).

Mesmo formada em Farmácia na Faculdade de Medicina do Rio de Janeiro e de sua experiência com o ensino de Química, Física e História Natural na Escola Normal de Niterói, onde exercia o magistério desde 1922, não obteve êxito nos dois concursos para concorrer à cadeira de Química do CPII, realizados, respectivamente, em 1934 e 1939, embora destacando-se dos demais candidatos na prova escrita do primeiro concurso, o qual foi, contudo, anulado.

Além de sua atuação profissional, ela declarou na data de inscrição para o concurso para a cadeira de Química, de 1934, ter feito parte do serviço químico da Armada (Marinha), criando um veneno para ser utilizado em cascos de navio, com patente de invenção, numa época em que as mulheres não podiam atuar neste campo $^{17}$, e de pertencer a diversas Sociedades e Associações brasileiras e internacionais de Química, Farmácia, Direito e Educação, bem como da Associação de Professores Católicos ${ }^{18}$, e do Sindicato de Professores ${ }^{19}$ (MOSS, 1933; 1939).

\footnotetext{
17 Segundo Adilene Silva (2018), apesar da Marinha ter sido a primeira Força Armada a admitir mulheres, em 1981, a Escola Naval só veio a permitir pela primeira vez o ingresso de mulheres, porém, como Aspirantes, em seus cursos de graduação para formação de Oficiais do Corpo da Armada, do Corpo de Fuzileiros Navais e do Corpo de Intendentes da Marinha, a partir do Edital de 2013. Entretanto as vagas destinadas às mulheres foram exclusivamente para o Corpo de Intendentes da Marinha. Aspirantes na EN são os alunos e as alunas durante o Ciclo Escolar dos referidos cursos de formação. 18 Provavelmente trata-se da Associação de Professores Católicos do Distrito Federal, tratada por Lopes (2017).

19 Provavelmente, trata-se do Sindicato dos Professores do Ensino Secundário e Comercial do Distrito Federal, criado em 1931. A filiação para quem exercia cargos administrativos era proibida. No ano de sua criação, altera seus estatutos, passando a aceitar a filiação de educadores de todos os segmentos e níveis de ensino e a denominar-se Sindicato dos Professores do Distrito Federal (MARTINS, 2012).
} 


\section{HISTÓRIA}

\section{Dossiê: Ensino de História, História das Mulheres e Desigualdades Sociais no Brasil}

Sua participação nessas associações foi decisiva para embasar seu percurso e constituir sua identidade profissional, embora tenhamos encontrado poucos rastros de sua atuação na documentação analisada, sendo necessário recorrer à imprensa.

O percurso de Maria da Glória foi marcado pela opção por uma profissão predominantemente masculina. Além do magistério secundário, ela percorreu o campo educacional brasileiro, no período indicado, de uma maneira singular, tanto por ter se profissionalizado e se especializado em pesquisas junto ao serviço químico da Armada Brasileira, utilizando-se do método do professor alemão Dr. Dennstedt ${ }^{20}$, quanto por ter apresentado os resultados de seus trabalhos no $1^{\circ}$ e no $2^{\circ}$ Congresso de Farmacêuticos, realizados tanto no Rio de Janeiro, em 1922, quanto em São Paulo, em 1928. Suas pesquisas ainda orientaram sua prática e suas reflexões em relação ao ensino de Química, em sua prática na Escola Normal e nos Cursos Secundários e Profissionais, mesmo após ter se formado pela Faculdade de Direito do Rio de Janeiro, atuando como advogada (OLIVEIRA e COSTA, 2019a).

Em 1941, ela ministrou uma sessão magna como médico-jurista em uma Conferência sobre educação sexual, realizada na Bahia, juntamente com Walfredo Machado, bem como atuou como advogada de defesa de alguns integrantes do levante militar deflagrado, em 1935, nas cidades de Natal, Recife e Rio de janeiro, também conhecido como "Revolta Comunista" (Jornal do Brasil, 30 de junho, 1938, p.7).

Mesmo assim, ela não deixou de lecionar. Apareceu como membro da Congregação do Instituto de Educação ${ }^{21}$ e professora catedrática de Química, 44 anos após iniciar sua carreira como professora, ou seja, em 1966. Em 1971, encerrou sua carreira profissional, quando foi finalmente convocada para lecionar como professora concursada, agora no ensino de Educação Moral e Cívica, no CPII (D.O.U, 22 de abril, 1971, p.1107). Faleceu 8 anos depois, aos 75 anos, viúva e, aparentemente, sem deixar herdeiros.

\footnotetext{
${ }^{20}$ Atualmente, seu sobrenome é associado a um tipo de reação de rearranjo para a obtenção de piridinas: a síntese de Ciamician-Dennstedt. Na tese que ela apresentou no concurso de Química, seu método foi utilizado no procedimento de catálise.

${ }^{21} \mathrm{~A}$ Congregação do Instituto foi criada por ato de 10 de fevereiro de 1947, na primeira administração do Professor Mário da Veiga Cabral, e funcionava na sala Lourenço Filho, do prédio central do complexo do Instituto de Educação. CENTRO de Memória Institucional do ISERJ. Disponível em: $<$ http://cemiiseri.blogspot.com.br/2006/05/congregao-do-instituto-de-educao.html $>$. Acesso em 01 mai. 2018.
} 


\section{HISTÓRIA}

\section{Dossiê: Ensino de História, História das Mulheres e Desigualdades Sociais no Brasil}

Em 1927, outras três professoras foram admitidas, porém, também como substitutas ou auxiliares. Dentre elas, destaca-se Maria de Lourdes Nogueira, professora auxiliar de Português, que também militou em defesa das pautas anarquistas e feministas.

Era também escritora e chegou a publicar as obras: Fragmentos, Ensaios Literários e Amor e Arte. Também atuava na imprensa, onde publicou seus ensaios literários na Revista da Semana, durante 1926 e 1928, e na Revista Fon Fon, entre 1914 e 1920 (OLIVEIRA e COSTA, 2019b).

Já nestas primeiras publicações despontavam questões libertárias, as quais apareciam de forma sutil em seus escritos, diferentemente da fase em que escreveu na imprensa anarquista, no final da década de 1920, quando teve forte militância na imprensa do Rio de Janeiro e nos Movimentos Anarquista e Feminista, como indicou o estudo de Martins (2009).

Durante esse período, chegou a ser presa juntamente com o professor catedrático de Português do CPII, José Oiticica, com o qual chegou a participar, inclusive, de bancas de exames de alunos. Por ocasião da greve da Companhia Leopoldina, ela proferiu um discurso no comício da Praça da República, apontando o anarquismo como o caminho para a libertação. Além de participar de organizações grupais e protestos públicos, assinou artigos na imprensa libertária, tais como, $A$ Obra, A Razão e também em $A$ Voz do Povo. Além disso, participou da fundação da Liga Feminista de Estudos Sociais, do $1^{\circ}$ Congresso Feminista Brasileiro e da Legião da Mulher Brasileira. Ela participou também da comissão organizadora do $1^{\circ}$ Congresso Feminista Brasileiro, cuja realização estava prevista para ocorrer entre $1^{\circ}$ a 15 de abril de 1921, do Partido Republicano Feminino (O Combate, 1 de fevereiro, 1921, p.3).

Apesar de participar de alguns eventos de cunho feminista, seu nome passou a aparecer na imprensa atrelado ao campo educacional, tendo como foco suas publicações escritas. Devido à abrangência de movimentos em que atuou, de suas publicações e da longa atuação no CPII (1927 até 1949), cabe ainda novos estudos sobre esta professora.

Outra militante feminista, que por sua vez, atuou no internato, é Carmem Portinho, que deu aulas na turma suplementar de Aritmética, cargo que ocupou por 3 anos (1927-1929) (COSTA e OLIVEIRA, 2019c), após ter cursado Engenharia pela 


\section{HISTÓRIA}

Dossiê: Ensino de História, História das Mulheres e Desigualdades Sociais no Brasil

Escola Politécnica da Universidade do Brasil - concluída em 1926 - até o retorno do professor catedrático Almeida Lisboa ${ }^{22}$, que estava em viagem para o exterior, o qual impunha resistência à Reforma no ensino de Matemática, aspirada por Euclides Roxo.

Em 1939, ganhou o título de urbanista, defendendo a tese intitulada: " $A$ futura capital do Brasil, no planalto de Goiás” (Jornal do Brasil, 17 de janeiro,1939, p.17).

Em relação às demais professoras, foi a única que conseguiu atuar no ensino superior. Além disso, foi uma das fundadoras da Federação Brasileira pelo Progresso Feminino (1922), atuando na vice-presidência, e membro e presidente da União Universitária Feminina, associação de mulheres universitárias, fundada em 1929 (BONATO, 2005). Durante toda sua trajetória, esteve à frente da luta pelos direitos das mulheres, até seu falecimento em 2001 (SCHUMAER, 2001).

Sobre Aimée Ruch, que atuou como professora de Francês nas turmas suplementares, encontramos, a princípio, poucas informações. Sabe-se que era irmã e parceria profissional de Gastão Ruch, professor catedrático do CPII, junto com o qual fundou uma escola particular. No livro Memória de estudante, de Fernando Segismundo, ex-aluno do CPII, há referências sobre a escola primária dos irmãos Ruch - Aimée e Gastão - localizada na travessa do Ouvidor, n.10, no centro do Rio de Janeiro, na qual o autor da biografia teria estudado, antes de 1927, ano em que também ingressou no CPII, como aluno.

Além disso, Segismundo cita em suas memórias o casamento de Aimée Ruch com Nelson Romero, filólogo, que também lecionou no CPII, como professor de Italiano. Este diplomou-se pela Universidade Gregoriana de Roma, Itália, em 1913, e era membro da Academia de Letras do Rio de Janeiro, da Academia Sergipana de Letras, da Academia de Filosofia (RJ) e membro fundador da Academia Brasileira de Filologia, com publicações sobre o Latim (SEGISMUNDO, 1927).

Nelson Romero teria participado do concurso para catedrático de italiano, concorrendo com Nella Aita, a primeira a prestar concurso para professor catedrático do CPII, em 1921. Ela ficou classificada em $4^{\circ}$ e ele em $7^{\circ}$ lugar. Contudo,

22 Conforme João Bosco Pitombeira de Carvalho et al. (2000, p. 415-424), o professor Almeida Lisboa critica os programas de Matemática elaborados por Euclides Roxo, em 1929, para o CPII. Almeida afirma que... "na qualidade de mais antigo professor catedrático de Matemática do Colégio Pedro II, declaro não ter colaborado, nem de leve, nos seus atuais programas de Matemática". Os autores concluem que Almeida Lisboa era partidário do ensino tradicional da Matemática. 


\section{HISTÓRIA}

Dossiê: Ensino de História, História das Mulheres e Desigualdades Sociais no Brasil posteriormente, ele ingressou no CPII como professor de italiano, enquanto não foram encontrados vestígios da atuação dela na instituição.

Dentre as produções intelectuais de Aimée Ruch, podemos citar o livro: Anthologia franceza, o qual foi utilizado como livro escolar no programa de ensino do CPII. Tamanho foi o sucesso da obra publicada por ela, que a mesma ficou em circulação e sendo divulgada na imprensa de 1930 até meados de 1936, contando com reedições em 1934, 1937 e 1940. Contudo, em 1935, outras obras passaram a ser divulgadas na imprensa, como escritas em parceria com o seu irmão Gastão Ruch: Versões Gradativas de Francês, para a $1^{\mathrm{a}}$ e $2^{\mathrm{a}}$ séries, e o Curso de Francês preliminar, os quais estavam à venda na Livraria Moderna, em 1937, porém, ao nos deparamos com as capas dos livros, percebe-se que somente ele foi identificado como autor das obras (O imparcial, 21 de julho, 1935, p.2;11 de março, 1936, p.1;15 de março, 1937, p.1; 15 de abril, 1939, p.1).

Embora possamos considerar a hipótese de que Gastão Ruch tenha sido um professor catedrático identificado como um dos "homens mundo", letrado e com cultura geral, o seu percurso nos indica vínculos com os conhecimentos de História das Civilizações, ao passo que sua irmã, Aimée Ruch, é quem atuava lecionando Francês. Desse modo, o apagamento de sua autoria, nestas obras, se configurou mais como uma estratégia editorial para publicação de uma obra de autoria feminina, depois que seu irmão, que a apoiava em seus projetos, já havia falecido.

Ela permaneceu atuando no CPII e oferecendo aulas particulares de Francês até seu falecimento, em 1945 (CORREIO DA MANHÃ, 1945).

\section{Considerações finais}

Falar do pioneirismo destas quatro professoras, Aimée Ruch, Carmem Portinho, Maria de Lourdes e Maria da Glória, no ensino secundário, é indicar caminhos para se pensar como as particularidades de seus percursos são estabelecidas nas relações que estabeleceram com as instituições, com seus pares e com os demais membros da sociedade em que estavam inseridas, e levando ainda em consideração a imagem construída acerca de si mesmas. 


\section{HISTÓRIA}

Dossiê: Ensino de História, História das Mulheres e Desigualdades Sociais no Brasil

Nesse sentido, pode-se perceber as estratégias utilizadas pelos professores que ocupavam o cargo de catedráticos no CPII para delimitarem seus espaços de atuação, buscando distinguirem-se delas, na instituição. Essas atitudes encobriam o fato de que buscavam manter uma hierarquia em relação às mulheres no que tange à profissão.

Estas hierarquias não se restringiram à diferença entre homens e mulheres. Elas existiam entre as próprias mulheres, uma vez que a maioria, naquela época, não tinha acesso à instrução, como também entre os homens, gerando categorias e identidades profissionais distintas. Como vimos, existiam várias categorias de professores no CPII, sendo apenas os professores catedráticos, ou os homensmundo, aptos a tomar decisões importantes em relação ao programa de ensino e seleção de professores, por exemplo.

Mesmo diante disso, não se pode descartar o protagonismo dessas professoras, bem como suas contribuições para o campo literário, acadêmico, científico e educacional, que foram ocultadas ou até mesmo desconsideradas, tanto por aqueles que detinham o poder de escolha naquele momento quanto historicamente. A presença de mulheres militantes, anarquistas e feministas, em um espaço marcadamente masculino acarretou mudanças no cenário educativo da instituição e do ensino secundário. Constatou-se, desde então, maior presença de mulheres, tanto no corpo docente quanto discente, ainda que os professores catedráticos tenham buscado estratégias de manutenção de seus privilégios no CPII, ao não permitirem o ingresso destas mulheres como catedráticas, visto que eram eles que integravam a Congregação que elegia os professores, os programas e manuais de ensino.

Estas mulheres, embora as tentativas de silenciá-las, atuaram tanto no contexto educacional quanto na produção científica, trazendo contribuições para o programa de ensino, interferindo nas práticas de ensino e na configuração da identidade do magistério secundário e, por que não dizer, no Programa Institucional do CPII.

Com isso, o estudo se deteve em trazer particularidades sobre o percurso profissional dessas professoras e suas trajetórias de vida. Este estudo integra uma pesquisa mais ampla sobre o percurso destas professoras e os levantamentos aqui apontados esboçam os primeiros caminhos traçados pela pesquisa, a qual tem se 


\section{HISTÓRIA}

Dossiê: Ensino de História, História das Mulheres e Desigualdades Sociais no Brasil desdobrado em novos trabalhos e publicações, buscando aprofundar a análise sobre a identidade profissional destas mulheres que atuaram no ensino secundário.

Escrever a história dessas mulheres é sair do silêncio em que elas estavam confinadas e no qual elas não se encontravam sozinhas. Como aponta Perrot (2012, p.16) é sobre elas que "o silêncio pesa mais". Primeiramente, devido a sua invisibilidade nos espaços públicos, que, por muito tempo, mereceu interesse e relato. E mesmo quando ocuparam esses espaços, foram pouco vistas. Nesse sentido de romper com o silenciamento dessas mulheres, as fontes do NUDOM assumiram papel relevante de dar visibilidade ao papel exercido por essas professoras não apenas no campo educacional, como nos demais setores da sociedade.

\section{Referências}

ALMEIDA, Jane Soares de. Mulher e educação: a paixão pelo possível. São Paulo: UNESP, 1998.

ALVES, R. L. Trajetórias femininas no Colégio Pedro II. In: 2 ANPUH - XXV Simpósio Nacional de História. Fortaleza, 2009.

ANDRADE, Vera Lúcia. C. Q. Colégio Pedro II: patrimônio e lugar de memória da educação brasileira. In. GASPARELLO, A. M. \& VILLELA, H. O. S. (eds.). Educação na história: intelectuais, saberes e ações instituintes. Rio de Janeiro: Mauad X, 2016, p.101-116.

Colégio Pedro II: o feminino como exceção. [S.I.:s.n.], 2000. 9 f.

BONATO, Nailda Marinho da Costa. O fundo Federação Brasileira pelo Progresso Feminino: uma fonte múltipla para a história da educação das mulheres. Acervo, Rio de Janeiro, v.18, nº 1-2, p.131-146, jan./dez. 2005.

BRASIL. Decreto n 19.890 de 11 de abril de 1931. Reforma Francisco Campos. Coleção de Leis do Império e da República, 1981.

. Decreto $\mathrm{n}^{\circ}$ 2.006, de 24 de outubro de 1857. Disponível em:

<https://www2.camara.leg.br/legin/fed/decret/1824-1899/decreto-2006-24-outubro1857-558097-publicacaooriginal-78997-pe.html>. Acesso: 30 abr.2020.

. Decreto $n^{\circ}$ 21241, de 1932. Disponível em:

<http://www.planalto.gov.br/ccivil 03/decreto/1930-1949/D21241.htm>. Acesso em 20 mai.2020. 


\section{HISTÓRIA}

Dossiê: Ensino de História, História das Mulheres e Desigualdades Sociais no Brasil

Decreto $n^{0}$ 18564, de 15 de janeiro de 1929. Disponível em:

$<$ https://www2.camara.leg.br/legin/fed/decret/1920-1929/decreto-18564-15-janeiro1929-502422-publicacaooriginal-1-pe.html>. Acesso em 20 mai.2020.

Decreto $n^{\circ}$ 2.006, de 24 de outubro de 1857. Disponível em:

<https://www2.camara.leg.br/legin/fed/decret/1824-1899/decreto-2006-24-outubro1857-558097-publicacaooriginal-78997-pe.html>. Acesso 30 abr. 2020.

CARVALHO, João Bosco Pitombeira de, WERNECK, Ana Paula Lellis Deborah Silva CRUZ, Enne Mônica Baptista da Costa Priscilla Rangel. Euclides Roxo e o movimento de reforma do ensino de Matemática na década de 30 . In: R. bras. Est. pedag. Brasília, v. 81, n. 199, set./dez. 2000, p. 415-424.

COSTA, Nailda Marinho; XAVIER, Libania. El associativismo de mujeres em Brasil y las tesis de Branca Canto de Melo en el primer Congreso Internacional Feminista (1922). In. GONZÁLEZ PEREZ, Teresa (Coord.) Le educación de las mujeres en Iberoamérica: análisis histórico. Gobierno de Canarias. Tirant Humanidades: Valencia, 2019. P. 375-406;

COSTA, Suely G. Gênero e história. In: ABREU, Martha; SOIEHT, Rachel (orgs). Ensino de História; conceitos, temáticas e metodologia. Rio de Janeiro: Casa da Palavra: Faperj, 2003, p. 187- 208.

COLÉGIO PEDRO II. Disponível em:

$<$ http://cp2.g12.br/118progesp/index.php?option=com content\&view=article\&id=1865 $\geq$ e < http://cp2centro.net/?p=4765 >. Acesso em 15 mai. 2020.

CORREIO DA MANHÃ. 18 de novembro, 1945.

COUTTO, P. Relatório concernente aos anos letivos de 1926 e 1927.

Apresentado ao Exmo. Sr. Diretor Geral do Departamento Nacional do Ensino por Pedro do Coutto, Diretor do Internato. Rio de Janeiro: Colégio Pedro II - Internato, 1928.

DASSIE, Bruno Alves. Euclides Roxo e a constituição da educação matemática no Brasil. Tese de doutorado. Programa de Pós-graduação em Ciências Humanas e Educação. PUC-Rio, Rio de Janeiro. Disponível em https://www.maxwell.vrac.pucrio.br/colecao.php?strSecao=resultado\&nrSeq=12024@1 Acesso em 30/04/2020

As propostas pedagógicas de Euclides Roxo para o ensino de Matemática na escola secundário brasileira. Boletim GEPEM. n.59, jul. 2011, p.81-94.

D.O.U. 22 de abril, 1971, p.1107.

DUBET, F. Le Declin de l’Institution. Paris: Éditions du Seuil, 2002. 


\section{HISTÓRIA}

Dossiê: Ensino de História, História das Mulheres e Desigualdades Sociais no Brasil

ESCRAGNOLLE DORIA, Luiz Gastão de. Memória histórica. Prof. Emérito do Collegio Pedro Segundo. Commemorativa do $1^{\circ}$ Centenário do Collegio de Pedro Segundo (2 de dezembro de 1837 - 2 de dezembro de 1937). Publicação oficial sob os auspícios do Ministério da Educação. Rio de janeiro, 1939.

GAMA, Zadig Mariano Figueira, MELLO, Celina Maria Moreira. Luiz Gastão d'Escragnolle Dória: um polígrafo das Letras Brasileiras. Revista Soletras. n.34, 2017.

GOMES, Angela de Castro e HANSEN, Patrícia Santos (Orgs). Intelectuais mediadores: práticas culturais e ação política. Rio de Janeiro: Civilização Brasileira. 2016.

GUIMARÃES ROXO, E. M. Relatório concernente aos anos letivos de 1925 e 1926. Apresentado ao Exmo. Sr. Diretor Geral do Departamento Nacional do Ensino pelo Professor Euclides de Medeiros Guimarães Roxo, Diretor do Externato. Rio de Janeiro: Colégio Pedro II, 1928.

ISERJ. Centro de Memória Institucional. Disponível em:

<http://cemiiserj.blogspot.com.br/2006/05/congregao-do-instituto-de-educao.html> Acesso em 01 mai. 2018.

JORNAL DO BRASIL. 30 de junho, 1938, p.7. 17 de janeiro,1939, p.17.

LOPES, Eliana Marta Teixeira. Da sagrada missão pedagógica. 2 ed. Belo Horizonte: Autêntica, 2017.

MARINHO, Nailda. A engenheira militante feminista Carmem Portinho: a atuação na União Universitária Feminina. GASPARELLO, Arlette Medeiros; VILLELA, Heloisa de Oliveira (orgs.). Educação na história: intelectuais, saberes e ações instituintes. Rio de Janeiro: Mauad X, 2016. p.215-232.

MARTINS, Thais da Silva Alves Martins. A docência em suas dimensões profissionais, políticas e culturais: um estudo sobre a escola do professor do Sinpro-Rj (2000-2010). Dissertação de Mestrado apresentado ao Programa de PósGraduação em Educação da Universidade Federal do Rio de Janeiro. Rio de Janeiro, 2012.

MARTINS, Angela Maria Roberti. A invisibilidade de Maria de Lourdes Nogueira: mulher, militante, libertária. Boletim do Núcleo de Pesquisa Marques da Costa. ano IV, n.12, jun, 2009.

MENDONÇA, A. W. P. C. Apresentação: O Colégio Pedro II e seu impacto na constituição do Magistério Público Secundário no Brasil (1837-1945). Revista Brasileira de História da Educação, v. 15, p. 167-171, 2015. 


\section{HISTÓRIA}

Dossiê: Ensino de História, História das Mulheres e Desigualdades Sociais no Brasil

MENDONÇA, Ana Waleska P. C., SOARES, Jefferson da Costa, LOPES, Ivone Goulart. A criação do Colégio de Pedro II e seu impacto na constituição do magistério público secundário no Brasil. In: Anais do VII Congresso Brasileiro de História da Educação. UFMT, MT: Cuiabá, 2013.

MOSS, Maria da Glória. Processo catalítico de análise orgânica: catálise. Rio de Janeiro: TYP. América, 1933.

MOSS, Maria da Glória. Catálise (tese). Rio de Janeiro: TYP. América,1939.

NUNES, Clarice. As políticas públicas de educação de Gustavo Capanema no governo Vargas. In. BOMENY, Helena et. al. (org.). Constelação Capanema: intelectuais e políticas. Rio de Janeiro: Editora FGV, 2001. p.103-125.

O COMBATE. 1 de fevereiro, 1921, p.3.

O IMPARCIAL. 21 de julho, 1935, p.2.

.11 de março, 1936, p.1.

15 de março, 1937, p.1.

15 de abril, 1939, p.1.

OLIVEIRA, Paloma Rezende de; COSTA, Nailda Marinho. O percurso da professora Maria da Glória Ribeiro Moss no Colégio Pedro Pedro II: "o famoso concurso de química” (1926-1939). Revista HISTEDBR On-line, Campinas, SP, v.19, p.1-21, 2019.

As estratégias identitárias construídas pelas mulheres para ingressarem como professoras de ensino secundário do Colégio Pedro II. Anais do XI Seminário Nacional do Histedbr. Uberlândia: Navegando publicações, 2019.p.305-319.

. Carmem Portinho: "Uma engenheira que lutou para vencer: de professora de matemática a chefe de Departamento". In: Anais da 39a reunião da Anped. Niteroi, 2019.

PERROT, Michelle. Minha história das mulheres. Trad. Angela M. S. Côrrea. $2^{\mathrm{a}}$ ed. São Paulo: Contexto, 2012.

SAFFIOTI, Heleieth lara Bongiovani. A mulher na sociedade de classes: mito e realidade. $3^{a}$ ed. São Paulo: Expressão Popular, 2013.

SANTOS, B. B. M. O Núcleo de Documentação e Memória do Colégio Pedro II e sua importância para a preservação do patrimônio histórico e cultural da educação brasileira. In: BONATO, N. M. C. \& XAVIER, L. (eds.). A história da educação no Rio de Janeiro: identidades locais, memória e patrimônio, Rio de Janeiro: Letra Capital, 2013, p.36-44. 


\section{HISTÓRIA}

Dossiê: Ensino de História, História das Mulheres e Desigualdades Sociais no Brasil

SCHELBAUER, Analete Regina. O método intuitivo e lições de coisas no Brasil do século XIX. In: STEPHANOU, Maria e BASTOS, Maria Helena Camara. Histórias e memórias da educação no Brasil. Vol. II - Século XIX. Petrópolis: Vozes, 2a . Ed., 2006, p. 132-149.

SCHUMAER, Maria Aparecida. Pioneiras da ciência no Brasil. In: VITRUVIRUS, ano 2, ago, 2001.

SEGISMUNDO, Fernando. Memória de estudante. 1927.

SILVA, Adilene Cunegundes da. $O$ ingresso e a permanência da primeira turma das aspirantes no curso de graduação da escola naval (2014-2017). Dissertação de mestrado. PPGEDU -UNIRIO, Rio de Janeiro, 2018.

SOARES, Jefferson da Costa e SILVA, Gustavo da Motta. Dentre a reforma Rocha Vaz e o Estado Novo: os professores suplementares do Colégio Pedro II. RBHE. v. 22, n. 56, set./dez., 2018.

SOARES, Jefferson da Costa. Dos professores estranhos aos catedráticos: aspectos da construção da identidade profissional docente no CPII (1925-1945). Tese. Programa de Pós-Graduação em Ciências Humanas e Educação. RJ: PUCRJ, 2014.

SOUZA, G. M. F. K. Euclides Roxo: debates sobre o ensino da matemática no começo do sáculo XX. Dissertação de mestrado profissional. Instituto de Matemática, Estatística e Computação científica da UNICAMP. Campinas, SP, 2010.

VALENTE, Wagner Rodrigues. História das Disciplinas Escolares no Brasil: contribuições para o debate. Bragança Paulista: EDUSF, 2003.

ZUCCO, Maise Caroline. "Circulação de saberes: publicações brasileiras sobre mulheres, gênero e feminismos no depósito legal (1960-1999)", Acervo, Rio de Janeiro, v. 33, n. 2, p. 27-42, maio/ago. 2020.

ZUIN, Elenice de Souza Lodron. Euclides Roxo: pelos caminhos da Metrologia. Caminhos da Educação Matemática em Revista/On line. v. 5, n. 1, 2016, p.93105. 